\title{
Políticas públicas de emprego e renda no Paraná e sua efetividade
}

\author{
Public policies for employment and income and its effectiveness in Paraná state
}

Políticas públicas de empleo y renta en Paraná y su efectividad

\author{
Fernanda Almeida da Silva Rosa ${ }^{1}$ \\ Silvio Roberto Stefano ${ }^{1}$ \\ Luiz Fernando Lara $^{2}$ \\ Márcio Luiz Bernardim ${ }^{1}$
}

Recebido em: 29/07/2019; revisado e aprovado em: 18/12/2019; aceito em: 13/01/2020

DOI: http://dx.doi.org/10.20435/inter.v22i2.2661

\begin{abstract}
Resumo: Os governos devem desenvolver políticas públicas de emprego e renda voltadas para a qualificação profissional, inclusão produtiva e promoção do emprego formal. A Teoria do Capital Humano defende que, quanto mais uma pessoa investe em conhecimento, maiores suas chances de alcançar melhores posições no mercado de trabalho e também aumentar a renda. Nesse contexto, o objetivo de pesquisa foi analisar as políticas públicas de emprego e renda na cidade de Ponta Grossa e suas relações nos níveis de emprego formal no período de 2015 a 2017. Esta pesquisa caracterizou-se como descritiva, com abordagem de métodos mistos, e a coleta de dados ocorreu por meio de entrevistas semiestruturadas e aplicação de questionários. Para análise, utilizou-se a técnica de análise do conteúdo e testes estatísticos diversos. Os resultados mostraram que quatro instituições públicas estão envolvidas com as políticas de emprego e renda da cidade, sendo elas a Agência SINE, a Sala da Qualificação, o Serviços de Obras Sociais e o Conselho Municipal do Trabalho. Os resultados da pesquisa com os trabalhadores apontaram que os pesquisados estão satisfeitos com as políticas atuais. Nas entrevistas realizadas com os representantes das empresas, ficou evidente o interesse e a satisfação com as políticas, principalmente as voltadas à qualificação profissional, mas com lacunas existentes. Por fim, apresentou-se uma agenda com algumas sugestões para aperfeiçoamento das políticas existentes. Palavras-chave: mercado de trabalho; Teoria do Capital Humano; emprego; qualificação profissional; Ponta Grossa.
\end{abstract}

Abstract: Governments should develop public employment and income policies aimed at professional qualification, productive inclusion, and promotion of formal employment. The Human Capital Theory, originated from this thinking, defends that the more a person invests in knowledge, the greater his/her chances to reach better positions in the job market and also to increase his/her income. In this context, this study aimed to analyze the public policies of employment and income in Ponta Grossa city, Brazil, and its relations with the levels of formal employment from 2015 to 2017. This research was characterized as descriptive, with a mixed-methods approach, and the data collection took place through semi-structured interviews and questionnaires. For the analysis, the technique of interpreting the content and diverse statistical tests were used. The results showed that four public institutions are involved with the employment and income policies of the city, namely the SINE agency, the Qualification Room, Social Project Services, and the Municipal Council for Work. The research results with the workers pointed out that the surveyed ones are satisfied with the current policies. In the interviews carried out with the companies' representatives, the interest and satisfaction with the policies were evident, mainly those related to professional qualification. Lastly, was presented an agenda with some suggestions to improve the currently offered policies.

Keywords: labor market; Human Capital Theory; employment; professional qualification; Ponta Grossa.

Resumen: Los gobiernos deben desarrollar políticas públicas de empleo e renta dirigidas a la calificación profesional, la inclusión productiva y la promoción del empleo formal. La Teoría del Capital Humano sostiene que cuanto más invierte una persona en conocimiento, mayores son sus posibilidades de lograr mejores posiciones en el mercado laboral y también aumentar la renta. En este contexto, el objetivo de la investigación fue analizar las políticas públicas de empleo e renta en la ciudad de Ponta Grossa, Brasil, y sus relaciones en los niveles de empleo formal en el período de 2015 a 2017. Esta investigación se caracterizó como descriptiva, con enfoque de métodos mixtos, y la recopilación de datos se realizó a través de entrevistas semiestructuradas y la aplicación de cuestionarios. Para el análisis, se utilizó la técnica de análisis de contenido y varias pruebas estadísticas. Los resultados mostraron que cuatro instituciones públicas están involucradas con las políticas de

\footnotetext{
${ }^{1}$ Universidade Estadual do Centro-Oeste do Paraná (UNICENTRO), Guarapuava, Paraná, Brasil.

2 Universidade Estadual de Ponta Grossa (UEPG), Ponta Grossa, Paraná, Brasil.
} 
empleo e ingresos de la ciudad, como la Agencia SINE, la Sala de Calificación, los Servicios de Obras Sociales y el Consejo Municipal de Trabajo. Los resultados de la investigación con los trabajadores señalaron que los encuestados están satisfechos con las políticas actuales. En las entrevistas con los representantes de las empresas, se evidenció el interés y la satisfacción con las políticas, especialmente aquellas enfocadas en la calificación profesional, pero con las brechas existentes. Finalmente, se presentó una agenda con algunas sugerencias para mejorar las políticas existentes.

Palabras clave: mercado de trabajo; Teoría del Capital Humano; empleo; calificación profesional; Ponta Grossa.

\section{INTRODUÇÃO}

Pesquisar as políticas públicas de emprego e renda implica apresentar, neste estudo, uma visão mais específica sobre as estratégias governamentais utilizadas com o objetivo de beneficiar a população. Estratégias que são essenciais para ajudar a amenizar os problemas do desemprego, o crescimento das formas atípicas e/ou precárias de trabalho, a exclusão social e a pobreza (COLBARI; RAINHA, 2014).

No Brasil, atualmente, entre as principais políticas públicas de emprego e renda (PPER) desenvolvidas em nível federal e estadual, destacam-se o Sistema Nacional de Emprego (SINE); Políticas de Juventude; Intermediação de Mão de Obra (IMO) do SINE e Qualificação Profissional (BRASIL, 2017). Para a qualificação profissional, tem-se o Plano Nacional de Qualificação (PNQ), que está entre as principais PPER do governo brasileiro. Esta política é orientada à inclusão social, que entende a qualificação profissional como uma relação social, a qual proporciona aos trabalhadores, além do conhecimento, maior autonomia no processo de trabalho e maiores salários. Isso reflete também nos propósitos empresariais, pois, quanto mais qualificado o empregado, maior a produtividade e competitividade no mercado (MARINHO; BALESTRO; WALTER, 2010).

Ao enfatizar essa visão, tal política vem ao encontro de teorias que tratam da relação entre educação e trabalho. De acordo com Castro (2006), ao escrever Riqueza das Nações, Adam Smith foi o primeiro a discutir que o aumento da produtividade está diretamente relacionado à educação. A partir de então, muitos outros trabalhos foram desenvolvidos relacionando educação e trabalho, afirmando não apenas sua relação com a produtividade, mas também com a remuneração percebida, com o desemprego, entre outros.

Entre as teorias que surgiram a partir da obra Riqueza das Nações, está a teoria do capital humano ( $\mathrm{TCH})$, que se apresenta como uma alternativa de desenvolvimento político e econômico, pois seus pressupostos defendem que o investimento em capital humano faz com que as pessoas sejam mais produtivas e tenham salários melhores, influenciando, assim, o progresso econômico (VIANA; LIMA, 2010). Essa teoria defende que, quanto mais educação e especialização tem um indivíduo, maior seria sua aceitação no mercado de trabalho, já que sua produtividade deveria ser maior. Com uma produtividade maior, os ganhos das empresas seriam elevados, bem como seu próprio nível de renda.

Neste sentido, a escolha do tema está relacionada ao interesse de analisar a efetividade das estratégias governamentais pertinentes às práticas de emprego e renda adotadas atualmente. Tal efetividade engloba o estudo das práticas desenvolvidas, bem como a opinião dos atores envolvidos. Considerando que cada estado e município possui, além das políticas federais, suas próprias políticas, apresenta-se o seguinte problema de pesquisa: Quais são as relações entre as políticas públicas de emprego e renda na cidade de Ponta Grossa, PR, e o emprego formal, à luz da teoria do capital humano? Assim, o objetivo principal deste estudo foi analisar as 
políticas públicas de emprego e renda na cidade de Ponta Grossa e suas relações com os níveis de emprego formal no período de 2015 a 2017. O artigo está estruturado em fundamentação teórica; procedimentos metodológicos; resultados e análises; e considerações finais.

\section{POLÍTICAS PÚBLICAS E A TEORIA DO CAPITAL HUMANO}

Além da importante natureza econômica, o mercado de trabalho é, antes de tudo, um espaço em que o indivíduo constrói sua vida social. A partir dessa colocação, afirma-se que existem três pontos que o influenciam. O primeiro, de ordem estrutural, diz respeito à cultura, ao ambiente social e às instituições em geral que o regem. O segundo se refere às condições macroeconômicas do país, com suas influências internas e externas. E, por fim, a quantidade e a qualidade da mão de obra ofertada que vão definir a capacidade produtiva do mercado. Esse último ponto resulta no valor agregado da mão de obra disponível (AMADEO et al., 2006).

Nesse cenário de influências, os governos são agentes fundamentais para a busca do equilíbrio do mercado de trabalho. Assim, suas atribuições direcionam-se às ações de regulamentação e regulação, também chamadas de instituições. Segundo Betcherman (2014), o arcabouço institucional em torno do mercado de trabalho inclui regulamentos como definição de salário mínimo e legislação de proteção ao emprego, regras para sindicatos e negociações coletivas, seguro-desemprego, programas ativos e passivos e legislação de equidade.

Os programas ativos e passivos são também chamados de políticas públicas ativas e passivas. A classificação padrão das políticas do mercado de trabalho, seguida pela base de dados da Organização para a Cooperação e Desenvolvimento Econômico (OCDE)/Gabinete de Estatísticas da União Europeia (EUROSTAT), considera como políticas "ativas" a assistência na procura de emprego, a formação profissional, a criação de emprego do setor público e emprego subsidiado no setor privado. Já nas políticas "passivas" estão o seguro-desemprego e benefícios sociais relacionados, que são pagos aos desempregados (MARTIN, 2015).

Nesse contexto, avaliar determinada política pública significa apresentar se ela está contribuindo positivamente para distribuição de bem-estar (FIGUEIREDO; FIGUEIREDO, 1986) e se essa política está promovendo mudanças nos sistemas econômico e social, destinados a alcançar os resultados desejados (SOUZA, 2002).

Para Souza (2002), a avaliação pode ser de processos ou de impactos. A primeira tem o objetivo de aferição da eficácia, que engloba a análise das diretrizes concebidas em relação ao alcance das metas desejadas. Já a segunda tem uma ambição mais ampla e complexa, pois se refere aos efeitos da legislação/plano/programa/projeto sobre seu público-alvo. Na última, é preciso ter: a) definições claras dos objetivos da política que se desdobrou em legislação/ plano/programa/projeto; b) especificação dos critérios de "sucesso"; e c) medidas de aferição do "sucesso" ou "fracasso" da política pública.

Nesse contexto, a teoria do capital humano (TCH) trata da relação entre educação, renda e, consequentemente, qualidade de vida dos indivíduos. Ela tem como precursores Gary Becker, Jacob Mincer e Theodore W. Schultz. Para Hersen (2009), a TCH explica que, quanto maior o nível de instrução do indivíduo, maior a sua eficiência no desenvolvimento da sua atividade laboral. Assim, ao se tornar mais produtivo, o trabalhador tem mais chance de obter uma remuneração maior em troca do trabalho desenvolvido. Ainda, a experiência adquirida eleva a destreza no trabalho, resultando no crescimento da produtividade da empresa e na própria remuneração. 
O principal objetivo da TCH é "[...] analisar de que forma os agentes econômicos decidem por investir mais ou menos tempo em educação" (KLOSOWSKI et al., 2013, p. 10). Esse objetivo originou-se na pesquisa de Mincer (1958), um dos primeiros a indicar a existência de correlação entre o investimento na formação educacional e profissional das pessoas e a distribuição de renda. Em seguida, Schultz (1964), por meio da comparação entre alguns países pobres, considera que há uma relação entre as taxas de crescimento econômico e os índices educacionais da população, sugerindo que a educação influencia no crescimento econômico de um país.

Lucas Jr. (1988) contribuiu, também, ao elaborar modelos que explicassem o desenvolvimento econômico dos países. Seus modelos incluíram as variáveis: acumulação física de capital e a mudança tecnológica; a acumulação de capital humano por meio da escolaridade; e a acumulação especializada de capital humano por meio da aprendizagem prática. Os resultados da sua pesquisa confirmam a importância do investimento em capital humano no desenvolvimento econômico de um país.

Becker (1993) parte do pressuposto de que o investimento em capital humano é a incorporação de recursos em atividades que influenciam a renda real futura das pessoas. Para ele, há muitas maneiras de investir nas pessoas: na escolaridade, em treinamento no trabalho, em assistência médica, no consumo de vitaminas e na aquisição de informações sobre o sistema econômico. Elas diferem nos efeitos relativos nos ganhos e no consumo, na quantidade de recursos tipicamente investidos, no tamanho dos retornos e na medida em que é percebida a conexão entre investimento e retorno. Mas todos melhoram as habilidades físicas e mentais das pessoas e, assim, aumentam as perspectivas de renda real (BECKER, 1993).

Apesar do grande número de defensores, a TCH sofre muitas críticas na academia. Segundo Frigotto (1993), essa teoria, como fundamentação teórica, tenta justificar as necessidades do sistema capitalista, favorecendo as desigualdades sociais existentes. Por sua vez, os marxistas teceram também críticas à TCH. De acordo com Almeida e Pereira (2000), elas podem ser agrupadas em três áreas: 1) contabilidade do desenvolvimento - é difícil precisar como a estrutura de formação do capital humano afeta a produção e a evolução das relações de classe; 2) distribuição de renda - a estrutura da distribuição de renda é determinada pela estrutura econômica e políticas públicas, e não pelo fato de os indivíduos assumirem posições de destaque econômico; e 3) políticas públicas - a educação e o retorno econômico teorizado não podem ser analisados com base em custo-benefício, precisam considerar outros aspectos relevantes da vida do indivíduo, tais como personalidade, consciência de classe, status familiar etc.

No Brasil, a educação profissional está ligada às políticas de emprego e renda, as quais visam elevar a qualidade do capital humano, com o objetivo de melhorar a condição social das pessoas e promover o desenvolvimento econômico, contribuindo para a diminuição do desemprego e possibilitando o aumento da renda das pessoas. De acordo com Marinho, Balestro e Walter (2010), a qualificação profissional dentro do Sistema Público de Emprego (SPE), no Brasil, tem mais de quinze anos e existe graças ao Fundo de Amparo ao Trabalhador (FAT).

Dentro dos mesmos objetivos da qualificação profissional, destaca-se o Programa Jovem Aprendiz, considerado uma política pública de emprego, que tem o objetivo de inserir o jovem no mercado de trabalho, juntando a teoria e a prática. "É um programa técnico-profissional que prevê a execução de atividades teóricas e práticas, sob a orientação pedagógica de entidade qualificada em formação técnico-profissional metódica e com atividades práticas coordenadas pelo empregador" (BRASIL, 2014, p. 13). 
Assim, observam-se duas situações, a inclusão de políticas de qualificação é importante para manter as pessoas no mercado de trabalho, seja nas mesmas ocupações ou não. As políticas podem oferecer reciclagem ou novas qualificações em outras áreas. Elas não precisam ser necessariamente para geração de emprego, mas podem ser direcionadas para geração de renda, no sentido de oportunizar que as pessoas sejam independentes e tenham seu próprio negócio. A seguir, apresentam-se os procedimentos metodológicos do estudo.

\section{PROCEDIMENTOS METODOLÓGICOS}

A metodologia do estudo envolveu métodos mistos, utilizando-se de métodos qualitativos e quantitativos para a coleta de dados (CRESWELL, 2010). Foram utilizados três instrumentos de pesquisas aplicados a três públicos diferentes. Uma versão da entrevista foi aplicada ao gestor ou responsável de cada órgão ou organização envolvido na ramificação das PPER voltadas para a qualificação profissional. Aos entrevistados deste instrumento, atribuíram-se os nomes fictícios A, B, C e D. A outra foi aplicada a uma amostra de quatro empresas usuárias do sistema público de emprego, especificamente para os profissionais da área de gestão de pessoas. Para esses entrevistados, foram também atribuídos nomes fictícios, conforme o ramo de atuação, sendo T, F, M e I.

Já o instrumento questionário foi direcionado à população que estava participando dos cursos de qualificação gratuitos. Ele contempla 33 questões fechadas, divididas em quatro blocos diferentes, com questões em vários tipos de escala. O universo pesquisado engloba 116 usuários. É importante ressaltar que a amostragem é do tipo cluster - indicada quando não é possível compilar os nomes dos pesquisados antes da aplicação, e por conveniência, ou seja, o tamanho da amostra é não probabilística (MALHOTRA, 2006). Quanto ao instrumento utilizado, foi adaptado do projeto Avaliação Externa do Programa Seguro-Desemprego, realizado pela Universidade de Brasília, cujos resultados estão disponíveis na obra Políticas Públicas de Emprego no Brasil: avaliação externa do Programa de Seguro-Desemprego, que tem como organizadores Marinho, Balestro e Walter (2010). Na análise das entrevistas, foi utilizada a técnica de análise de conteúdo. O Quadro 1 representa as categorias e subcategorias adotadas para este estudo.

Quadro 1 - Categorias de análise do conteúdo (entrevistas)

\begin{tabular}{|c|c|c|}
\hline Entrevistados & Categorias & Subcategorias \\
\hline \multirow{7}{*}{$\begin{array}{l}\text { Responsáveis pelos órgãos } \\
\text { públicos ou instituição } \\
\text { pública envolvida com a } \\
\text { política pública de emprego } \\
\text { e renda }\end{array}$} & \multirow{3}{*}{$\begin{array}{l}\text { Políticas públicas de } \\
\text { emprego e renda }\end{array}$} & Origem \\
\hline & & Objetivo \\
\hline & & Critérios de sucesso \\
\hline & \multirow{4}{*}{ Responsabilidade } & Atribuições \\
\hline & & Estratégia de desenvolvimento adotada \\
\hline & & Prática atual \\
\hline & & Sugestões ou reclamações \\
\hline \multirow{4}{*}{ Empresas usuárias } & \multirow{4}{*}{ Valor agregado } & Políticas direcionadas \\
\hline & & Frequência de utilização \\
\hline & & Benefícios percebidos \\
\hline & & Sugestões ou reclamações \\
\hline
\end{tabular}

Fonte: Elaborado pelos autores (2019). 
Como suporte e complementação na análise das entrevistas, foi utilizado o diário de pesquisa, que é um método de coleta de informações no qual é possível registrar as experiências dos eventos que ocorrerem durante a entrevista, como a experiência, os problemas e o contato com os entrevistados, por exemplo. Por meio dele, é possível observar os fatos descritos em seu contexto natural e espontâneo (FLICK, 2009).

Para a análise dos dados obtidos por meio do questionário, utilizou-se como base o software IBM SPSS Version 23. Inicialmente, foi realizada a análise utilizando-se da estatística descritiva (FIELD, 2011). Para isso, foram elencadas as frequências das variáveis escolhidas, bem como média, desvio-padrão e variância. Para discussão da relação entre as variáveis propostas no questionário, optou-se pelo teste de correlação. Por fim, utilizou-se do Teste Qui-Quadrado para identificar a existência ou não de relacionamento entre duas variáveis categóricas. No próximo tópico, são apresentados os dados originados da pesquisa, juntamente das análises e discussões.

\section{RESULTADOS}

\subsection{Delineamento das políticas públicas de emprego e renda: atribuições dos órgãos intermediadores}

Visando compreender quais órgãos estão por trás do desenvolvimento e da prática das PPER na cidade de Ponta Grossa, foram selecionadas para entrevista instituições públicas ligadas diretamente a elas, especialmente as voltadas para a qualificação profissional. No Quadro 2, são apresentados os órgãos que foram pesquisados, um resumo das políticas ou do projeto pertinentes a cada um, bem como a responsabilidade deles perante a sociedade. Esse quadro é parte da avaliação das políticas, conforme a explicação de Souza (2002).

Quadro 2 - Síntese das categorias de análise por órgão público pesquisado

\begin{tabular}{|c|c|c|c|c|}
\hline \multirow[b]{2}{*}{ Categorias } & \multicolumn{4}{|c|}{ Órgãos Pesquisados } \\
\hline & $\begin{array}{c}\text { Agência do } \\
\text { Trabalhador (SINE) }\end{array}$ & $\begin{array}{c}\text { Sala da Qualificação } \\
\text { (SQ) }\end{array}$ & $\begin{array}{c}\text { Serviços de Obras } \\
\text { Sociais (SOS) }\end{array}$ & $\begin{array}{l}\text { Conselho Municipal } \\
\text { do Trabalho (CMT-PG) }\end{array}$ \\
\hline $\begin{array}{l}\text { Políticas públicas } \\
\text { de emprego e } \\
\text { renda }\end{array}$ & $\begin{array}{l}\text { - Intermediar mão de } \\
\text { obra; } \\
\text { - Atender solicitantes } \\
\text { do seguro- } \\
\text { desemprego; } \\
\text { - Encaminhar pessoas } \\
\text { com deficiência } \\
\text { com o apoio de um } \\
\text { departamento do } \\
\text { Serviço Social. }\end{array}$ & $\begin{array}{l}\text { - Oferecer cursos } \\
\text { de qualificação } \\
\text { profissional } \\
\text { gratuitos para toda } \\
\text { a população; } \\
\text { - Oferecer vagas } \\
\text { de estágio para } \\
\text { a prefeitura e } \\
\text { qualificação. }\end{array}$ & $\begin{array}{l}\text { - Oferecer cursos } \\
\text { de qualificação } \\
\text { profissional gratuitos } \\
\text { para a população } \\
\text { vulnerável. }\end{array}$ & $\begin{array}{l}\text { Por si só, já é fruto } \\
\text { de uma política de } \\
\text { emprego. }\end{array}$ \\
\hline Responsabilidade & $\begin{array}{l}\text { Ser o elo entre o } \\
\text { empresário e o } \\
\text { trabalhador, com o } \\
\text { objetivo de colocar } \\
\text { o maior número de } \\
\text { trabalhadores no } \\
\text { mercado de trabalho } \\
\text { formal. }\end{array}$ & \begin{tabular}{|l|} 
Entender a \\
necessidade da \\
população em termos \\
de qualificação \\
profissional e \\
oferecer os cursos \\
conforme essa \\
necessidade.
\end{tabular} & $\begin{array}{l}\text { Entender a } \\
\text { necessidade da } \\
\text { população vulnerável } \\
\text { em termos de } \\
\text { qualificação } \\
\text { profissional e oferecer } \\
\text { os cursos conforme } \\
\text { essa necessidade. }\end{array}$ & $\begin{array}{l}\text { Apoiar, incentivar } \\
\text { e ajudar a dar } \\
\text { andamento, junto } \\
\text { ao Legislativo, das } \\
\text { demandas existentes. } \\
\text { E, ainda, cobrar o } \\
\text { Legislativo para fazer } \\
\text { leis que beneficiem o } \\
\text { trabalhador. }\end{array}$ \\
\hline
\end{tabular}

Fonte: Dados da pesquisa de campo (2019). 
Fundamentalmente, a prefeitura é quem fornece suporte para as quatro instituições pesquisadas, Agência do Trabalhador (SINE), Sala da Qualificação (SQ), Serviços de Obras Sociais (SOS) e Conselho Municipal do Trabalho (CMT-PG). O diretor da agência SINE informou que eles são responsáveis por vários programas voltados ao trabalhador, entre eles, os que foram destacados no Quadro 2, e também serviços de emissão da carteira de identidade e de trabalho; elaboração, impressão e entrega de currículos de forma gratuita, para quem precisa; e, uma vez por mês, o deslocamento da equipe até um bairro distante da cidade para levar todos os serviços para a população mais carente (Entrevistado A).

Sobre as práticas relacionadas à qualificação profissional, o Entrevistado A relatou que a agência tem cursos do ST que são oferecidos via Educação a Distância (EAD), mas eles são separados da agência. Outra modalidade de cursos oferecidos na agência é do Programa Nacional de Acesso ao Ensino Técnico (PRONATEC); esses cursos são disponibilizados para alguns beneficiários do Programa Seguro-Desemprego.

Já a Sala da Qualificação (SQ) e Serviços de Obras Sociais (SOS) estão voltados mais especificamente para projetos relacionados à qualificação profissional, sendo o SOS voltado especialmente para a população mais vulnerável. A SQ está vinculada à Secretaria Municipal de Indústria, Comércio e Qualificação Profissional (SMICQP), que oferece qualificação profissional gratuita a toda a população acima de 18 anos e com o ensino fundamental completo. "De acordo com uma das funcionárias, o setor existe desde 2006; por ele, já passaram três diretores, e agora tem uma diretora" (Diário de Campo).

Ela explicou que o órgão trabalha em duas frentes, na contratação e qualificação de estagiários e, também, com os cursos de qualificação para a população em geral. Para alcançar o objetivo principal, que é a geração de renda por meio da qualificação profissional, a equipe do setor trabalha, primeiramente, buscando as necessidades do mercado de trabalho, quais vagas não estão preenchidas por falta de profissionais qualificados e quais as dificuldades da população que não encontra colocação no mercado (Entrevistada B).

A sala da qualificação tem uma parceria forte com o Serviço de Obras Sociais (SOS) no que diz respeito à oferta de cursos de qualificação profissional (Diário de Campo). Este órgão é ligado à prefeitura e tem um setor específico chamado Cursos. Neste setor, duas assistentes sociais são responsáveis por administrar os cursos ofertados. De acordo com uma das assistentes sociais (Entrevistada C), o setor recebe verba da prefeitura que, antes, era disponibilizada pelo Conselho da Assistência Social e, agora, mais recentemente, é por meio da SMICQP.

A SQ e os Cursos do SOS trabalham em parceria e têm o mesmo objetivo de qualificação profissional; no entanto o público do SOS é mais seletivo, ou seja, os cursos são oferecidos para pessoas entre 18 e 59 anos, e a prioridade são as pessoas inseridas no Programa Bolsa Família; depois, os moradores de rua. Em seguida, os cursos são abertos para a demanda espontânea (na maioria das vezes, desempregados) e, por conseguinte, algumas vagas são reservadas para o público que procura a SQ (Entrevistada C).

Por fim, o CMT-PG é uma política criada para apoiar, incentivar e ajudar a dar andamento, junto ao Legislativo, das demandas de emprego e renda existentes. O CMT-PG foi criado pela Lei 5400/1996 e revogado pela Lei 11930/2014, a qual o torna de "caráter permanente e deliberativo, com a finalidade de estabelecer diretrizes e prioridades para as políticas de emprego e relações do trabalho no município" (PONTA GROSSA, 1996, p. 1). 
De acordo com o atual diretor (Entrevistado D), o CMT-PG é aquela equipe que sempre vai cobrar o resultado da agência do trabalhador e, em consequência, da prefeitura; além disso, intermedeia e cobra o Legislativo para fazer leis que beneficiem o trabalhador (Entrevistado D). 0 conselho é composto de maneira tripartite, com representantes dos sindicatos dos empregadores, dos empregados e do setor público, bem como de empregadores, entidades, faculdades - toda representatividade organizada da cidade tem um membro titular. A presidência é trocada anualmente e alterna entre representantes dos empregadores e empregados (Entrevistado D).

Notou-se que os quatro órgãos conseguem trabalhar em conjunto, mesmo que sem perceber. A agência fornece informações para todos os órgãos a respeito das necessidades dos empregadores e dos trabalhadores, nas questões de qualificação e de novas políticas. Todos os órgãos têm como base para as suas ações os acontecimentos/necessidades do SINE, ou seja, as necessidades das empresas e dos trabalhadores que são refletidas na agência.

Outro ponto que chamou atenção é que, ao contrário do que se pode pensar, nem todas as políticas de emprego e renda têm por objetivo fazer com que o trabalhador consiga um emprego. Nas políticas de qualificação, por exemplo, o intuito principal é fazer com que as pessoas gerem sua própria renda, dependendo ou não de um empregador. Diante disso, é possível afirmar que a prefeitura trabalha em prol não somente de empregos, mas também da geração de renda na cidade.

Para finalizar a apresentação dos resultados da pesquisa com os órgãos, o Quadro 3 mostra uma síntese das políticas encontradas, denominadas categorias de pesquisa, juntamente de sua origem, objetivo e critério de sucesso, chamados de subcategorias da pesquisa.

Quadro 3 - Síntese dos resultados das categorias e subcategorias das políticas públicas encontradas

\begin{tabular}{|c|c|}
\hline Categorias (Políticas) & Subcategorias \\
\hline \multirow{3}{*}{$\begin{array}{l}\text { Intermediação de mão } \\
\text { de obra }\end{array}$} & Origem: federal. \\
\hline & $\begin{array}{l}\text { Objetivo: ajudar o trabalhador a se recolocar no mercado de trabalho de } \\
\text { forma mais rápida. }\end{array}$ \\
\hline & Critério de sucesso: número de vagas preenchidas versus vagas oferecidas. \\
\hline \multirow{3}{*}{$\begin{array}{l}\text { Atendimento do } \\
\text { seguro-desemprego }\end{array}$} & Origem: federal. \\
\hline & Objetivo: dar apoio monetário temporário ao trabalhador desempregado. \\
\hline & Critério de sucesso: durar o menor tempo possível ou nem ser utilizada. \\
\hline \multirow{3}{*}{$\begin{array}{l}\text { Departamento do } \\
\text { Serviço Social no SINE }\end{array}$} & Origem: municipal. \\
\hline & $\begin{array}{l}\text { Objetivo: facilitar a colocação de mão de obra de pessoas com deficiência } \\
\text { no mercado de trabalho. }\end{array}$ \\
\hline & $\begin{array}{l}\text { Critério de sucesso: inserir o maior número de pessoas com deficiência no } \\
\text { mercado de trabalho. }\end{array}$ \\
\hline \multirow{3}{*}{$\begin{array}{l}\text { Cursos de qualificação } \\
\text { profissional gratuitos } \\
\text { para toda a população }\end{array}$} & Origem: municipal. \\
\hline & Objetivo: oferecer qualificação profissional gratuita para toda a população. \\
\hline & $\begin{array}{l}\text { Critério de sucesso: preencher todas as vagas dos cursos e inserir, ou } \\
\text { reinserir, as pessoas no mercado de trabalho. }\end{array}$ \\
\hline \multirow{3}{*}{$\begin{array}{l}\text { Programa de estágio } \\
\text { para a prefeitura e } \\
\text { qualificação para os } \\
\text { estagiários }\end{array}$} & Origem: municipal. \\
\hline & $\begin{array}{l}\text { Objetivo: dar oportunidade aos estudantes de colocar em prática o que eles } \\
\text { aprendem no ambiente escolar. }\end{array}$ \\
\hline & $\begin{array}{l}\text { Critério de sucesso: colocar mão de obra qualificada e com alguma } \\
\text { experiência no mercado de trabalho. }\end{array}$ \\
\hline
\end{tabular}




\begin{tabular}{|c|c|}
\hline Categorias (Políticas) & Subcategorias \\
\hline \multirow{3}{*}{$\begin{array}{l}\text { Cursos de qualificação } \\
\text { profissional gratuitos } \\
\text { para a população } \\
\text { vulnerável }\end{array}$} & Origem: municipal. \\
\hline & $\begin{array}{l}\text { Objetivo: qualificar a população carente para se colocar no mundo do } \\
\text { trabalho. }\end{array}$ \\
\hline & $\begin{array}{l}\text { Critério de sucesso: devolver a dignidade para as pessoas, colocando-as no } \\
\text { mundo de trabalho. }\end{array}$ \\
\hline \multirow{3}{*}{$\begin{array}{l}\text { Conselho Municipal } \\
\text { do Trabalho }\end{array}$} & Origem: municipal. \\
\hline & $\begin{array}{l}\text { Objetivo: cobrar os órgãos públicos eficiência nas políticas públicas de } \\
\text { emprego e renda para a população e para as empresas. }\end{array}$ \\
\hline & $\begin{array}{l}\text { Critério de sucesso: melhorar as políticas públicas de emprego e renda, } \\
\text { beneficiando a população e as empresas. }\end{array}$ \\
\hline
\end{tabular}

Fonte: dados da pesquisa de campo (2019).

\subsection{Políticas públicas de emprego e renda: visão dos usuários}

\subsubsection{Trabalhadores - Análises Estatísticas Descritivas}

Neste tópico, estão apresentados os dados coletados por meio do questionário aplicado aos participantes dos cursos oferecidos no SOS e nas carretas do SENAI em parceria com a Prefeitura de Ponta Grossa, nos meses de outubro e novembro de 2018, sendo abordadas 116 pessoas. O bloco 1 das questões contemplou questões relacionadas ao perfil dos pesquisados. Seus resultados apontaram que a maioria tem idade entre 18 e 30 anos, sendo 39,8\% do total. Apesar da pouca diferença, participaram da pesquisa um número maior de mulheres, que representam $53,5 \%$ do público pesquisado; $47,4 \%$ dos pesquisados têm como escolaridade o ensino médio completo; e 48,7\% não têm renda.

O bloco 2 da pesquisa, intitulado Trabalho, foi composto por seis questões que tratam do histórico profissional do entrevistado. Os resultados apontaram que 75,2\% afirmaram estar desempregados. No cruzamento das respostas das variáveis "estar trabalhando no momento" e "ocupação atual ou anterior", verificou-se que mais de cinquenta por cento, tanto das pessoas que estavam trabalhando no momento quanto das que estavam desempregadas, trabalham ou trabalhavam por conta própria, ou fazem trabalhos eventuais ou bicos. Isso reflete a realidade do mercado informal do Brasil. De acordo com o Instituto Brasileiro de Geografia e Estatística (PERET, 2018), em 2018, a soma de pessoas que atuam por conta própria com os que estão no mercado informal se mostrou superior ao total de empregados com carteira assinada. Em números, 33 milhões trabalhavam com carteira assinada, 23,8 milhões por conta própria, e 11,5 milhões trabalhavam sem carteira assinada.

O bloco 3 da pesquisa trata da questão qualificação. Os seus resultados apontaram que os meios de divulgação que mais atingiram os pesquisados foram TV, rádio e jornal. A busca por cursos de qualificação é motivada pela abertura de mais oportunidades de empregos. Assim, as expectativas com relação ao curso é conseguir trabalhar por conta própria ou arrumar um emprego. Além da abertura de novos empregos, as pessoas procuram novos cursos por ter afinidade com a técnica oferecida, devido à realidade da falta de emprego e, também, pela necessidade de ganhar mais dinheiro. Apesar do interesse na qualificação, quando questionados sobre a participação em alguma palestra, seminário ou congresso, 65,5\% disseram não ter participado de nenhuma dessa opções. A justificativa da não participação de 32,1\% foi por não terem conhecimento da ocorrência do evento, e 25,6\% afirmaram ser por falta de condições financeiras. 
No quesito qualidade dos cursos, é possível afirmar que os cursos ofertados oferecem uma aprendizagem técnica consistente e coerente com a realidade do dia a dia, e ainda despertam o interesse dos alunos para estarem sempre se aperfeiçoando e buscando novas oportunidades. Essa afirmação está baseada nas respostas das questões de aprendizagem e de vontade de fazer outros cursos, nas quais 56,3\% disseram que, ao final do curso, sentiram-se mais bem preparados para trabalhar sozinhos na área, e 93,3\% afirmaram que gostariam de fazer mais cursos.

A qualidade dos cursos e treinamentos influencia diretamente no conhecimento a ser adquirido, ou seja, quanto mais qualidade, maior a possibilidade de absorção das informações pelos participantes. Alguns pontos precisam ser considerados para garantir a qualidade do curso/treinamento ofertado: didática dos instrutores, preparo técnico, lógica nas informações, qualidade nos recursos, técnicas utilizadas pelos instrutores (MARRAS, 2011).

A respeito das expectativas que os entrevistados têm em relação ao futuro profissional, o resultado mostrou que a principal expectativa das pessoas que fazem os cursos é trabalhar por conta própria $(20,9 \%)$ ou conseguir um emprego (16,30\%). Essas respostas podem estar ligadas aos tipos de cursos oferecidos; por exemplo, manicure e cabeleireiro, os quais permitem que as pessoas possam optar por trabalhar por conta própria ou com carteira assinada.

As expectativas profissionais das pessoas em relação aos cursos oferecidos ou as qualificações recebidas estão também diretamente relacionadas ao desenvolvimento de carreira. Um curso pode ser o pontapé inicial para uma carreira, seja dentro de uma empresa, seja fora de uma. Ao contrário do que se pode pensar, a carreira não é mais uma preocupação ou vontade empresarial, mas sim do indivíduo, que busca sua independência financeira e ao mesmo tempo o sucesso profissional (ROSA; ZAMPIER; STEFANO, 2017).

Por fim, o bloco 4 da pesquisa trata da questão Empregabilidade, que trata de aspectos relacionados às ações da vida pessoal e também da opinião sobre a qualificação e o desemprego na cidade de Ponta Grossa. Essas questões estão diretamente relacionadas aos pilares que sustentam a empregabilidade. Conforme Minarelli (1995), os pilares são: a) adequação vocacional; b) saúde física e mental; c) competência profissional; d) idoneidade; e) reserva financeira e fontes alternativas, e f) relacionamentos.

Embora o número maior de pesquisados esteja desempregado, mais da metade deles foi ao médico nos últimos 12 meses para fazer uma consulta ou exame médico, buscando manterse apto para o trabalho. Sobre a restrição de crédito, 60,5\% dos pesquisados não têm restrição. Não possuir uma rede de contatos para auxiliar na recolocação no mercado de trabalho também é opção da maioria, que corresponde a 59,9\%.

Sobre a visão dos trabalhadores a respeito do mercado de trabalho na cidade de Ponta Grossa, as respostas podem ser resumidas como sendo a qualificação profissional um ponto de considerável importância na questão do desemprego. Neste sentido, Pochmann (2015) afirma que a intensificação da qualificação pode resultar na diminuição do desemprego, pois haveria adequação de mão de obra às exigências das empresas e resultaria, também, na elevação da qualidade dos postos de trabalho existentes. Entretanto a diminuição do desemprego não depende somente da qualificação, existem fatores como políticas governamentais de ajuste econômico, que interferem diretamente no nível de emprego de um país (POCHMANN, 2015).

Com um olhar mais crítico nessa "consciência" da classe trabalhadora da relação entre qualificação e trabalho/emprego, Coutinho (2014, p. 133-4) argumenta que "O capital humano se posiciona como limite e possibilidade de aumento de poder aquisitivo por parte dos trabalhadores, 
tendo tido grande recepção entre trabalhadores e capitalistas". Ao fazer essa afirmação, o autor entende que o capital humano transfere para o trabalhador a responsabilidade da qualificação, incutindo na sua mente a relação entre qualificação e aumento do poder aquisitivo.

\subsubsection{Coeficientes de correlação de Spearman}

A análise de correlação caracteriza-se por mostrar o grau de relacionamento linear entre duas variáveis (FIELD, 2011). A Tabela 1 apresenta a análise de correlação entre algumas variáveis socioeconômicas.

Tabela 1 - Correlação entre as variáveis socioeconômicas

\begin{tabular}{|c|c|c|c|c|}
\hline \multicolumn{2}{|c|}{ Variável } & Idade & $\begin{array}{c}\text { Grau de } \\
\text { escolaridade }\end{array}$ & $\begin{array}{c}\text { Renda mensal } \\
\text { individual }\end{array}$ \\
\hline \multirow{3}{*}{ Idade } & Coeficiente de Correlação & 1 & & \\
\cline { 2 - 5 } & Sig. & & & \\
\cline { 2 - 5 } & $\mathrm{N}$ & 113 & & \\
\hline \multirow{2}{*}{$\begin{array}{c}\text { Grau de } \\
\text { escolaridade }\end{array}$} & Coeficiente de Correlação &,$- 315^{* *}$ & 1 & \\
\cline { 2 - 5 } & Sig. &, 001 & & \\
\hline \multirow{2}{*}{$\begin{array}{c}\text { Renda Mensal } \\
\text { individual }\end{array}$} & Coeficiente de Correlação & 111 & 114 & \\
\cline { 2 - 5 } & Sig. &, $0217^{*}$ & 0,041 & 1 \\
\cline { 2 - 5 } & $\mathrm{N}$ & 112 &, 666 & 113 \\
\hline
\end{tabular}

Legenda: Sig = significância; $N$ = número de respondentes.

Fonte: Dados da pesquisa de campo (2019).

Com base nos resultados apresentados na Tabela 1, foi possível concluir, em relação ao público pesquisado, que à medida que o grau de escolaridade aumenta, a idade diminui, confirmando que os mais jovens têm mais escolaridade do que os mais velhos. Reis e Ramos (2011) relatam evidências de que as pessoas tendem a ter um grau de escolaridade maior do que seus pais, ou seja, quanto mais nova a geração, maiores são os níveis educacionais alcançados. Isso confirma a tese de que quanto melhor a condição intelectual e financeira dos pais, maiores serão as oportunidades educacionais dos filhos.

Entre as variáveis renda mensal e idade, os resultados apontaram que quanto maior a idade, maior a renda. Por fim, as variáveis renda mensal e grau de escolaridade tiveram uma correlação positiva quase imperceptível, possibilitando afirmar que a relação entre a escolaridade e renda não é estatisticamente significativa nesta amostra. No entanto a literatura apresenta na TCH os benefícios gerados pela escolaridade sobre a renda, considerando que os salários correspondem à produtividade, sendo observadas evidências "[...] em inúmeros estudos que estimaram uma função de rendimentos minceriana, a qual relaciona rendimentos e escolaridade e dá uma ideia da associação entre escolaridade e produtividade" (JACINTO, 2015, p. 257).

\subsubsection{Testes de Qui-Quadrado}

Neste tópico, estão apresentados os Testes de Qui-Quadrado realizados em algumas variáveis da pesquisa. O teste contribuiu para a análise e discussão de variáveis sociodemográficas, trabalho, qualificação e empregabilidade. 
Na primeira análise, o objetivo é saber se nesta amostra há ou não associação entre renda e gênero. A partir do resultado, é possível afirmar que, estatisticamente, não há associação entre renda e sexo, pois o resultado de $p=0,053$ é maior que 0,05 . Neste sentido, é possível afirmar que a renda não está relacionada ao gênero nesta amostra. Esse resultado vai contra a maioria dos achados na literatura; o estudo de Gonçalves e Teixeira (2017), por exemplo, apontou que no Estado de São Paulo existem diferenças salariais entre homens e mulheres, sendo a renda dos homens mais elevada, considerando os mesmos níveis de instrução. No entanto cabe salientar que os resultados apontaram também que os homens trabalham mais horas que as mulheres, o que pode justificar a diferença encontrada.

Outras variáveis também foram submetidas a testes e os resultados apontaram que, entre as variáveis "estar trabalhando no momento" e "estado civil", "motivação na escolha do curso" e "idade", há um relacionamento significativo. Há associação, ainda, entre as variáveis: "frequentou ou participou de algum curso, palestra, seminário ou congresso nos últimos 12 meses" em relação ao "sexo"; "possuir restrição de crédito" em relação com a "idade"; "possuir uma rede de contatos" com a "idade" e com "estado civil"; "está trabalhando no momento" em relação a "possui rede de contatos".

\subsubsection{Empresas - Análise qualitativa}

Neste tópico, são apresentados os resultados da pesquisa com os responsáveis pelas empresas na área de recursos humanos $(\mathrm{RH})$. Nele, está descrita a visão destes em relação às PPER ofertadas na cidade de Ponta Grossa. Quatro empresas foram pesquisadas entre os meses de dezembro de 2018 e janeiro de 2019, sendo duas do ramo de prestação de serviço, uma do comércio e uma da indústria. O Quadro 4 apresenta o perfil dos entrevistados.

Quadro 4 - Perfil dos respondentes das empresas

\begin{tabular}{|c|c|c|c|c|c|}
\hline Entrevistados & Sexo & $\begin{array}{c}\text { Idade } \\
\text { (anos) }\end{array}$ & $\begin{array}{c}\text { Tempo de } \\
\text { trabalho (anos) }\end{array}$ & Formação & Função \\
\hline$T$ & Feminino & 35 & 24 & Especialização em Psicologia & Analista de RH \\
\hline$F$ & Feminino & 24 & 1 & $\begin{array}{c}\text { Cursando Especialização em } \\
\text { Gestão de pessoas e coaching }\end{array}$ & Assistente de RH \\
\hline M & Masculino & 29 & 8 & Graduação em Administração & Gerente \\
\hline I & Masculino & 22 & 2 & Cursando Psicologia & Assistente de RH \\
\hline
\end{tabular}

Fonte: dados da pesquisa de campo (2019).

A primeira entrevistada foi uma profissional de uma empresa que atua no ramo de prestação de serviço, na área do transporte. Denominada de entrevistada T, ela trabalha há mais de vinte anos na empresa. A segunda empresa pertence ao ramo do comércio farmacêutico, representada pela entrevistada $F$, que atua a um ano na empresa. A terceira empresa é do ramo de prestação de serviço na área de mão de obra, sendo seu representante o entrevistado $M$, que tem mais de cinco anos de empresa e trabalha na área administrativa. A quarta empresa é da área industrial, representada pelo entrevistado I, que tem seis meses de empresa.

Os entrevistados responderam sobre a relação empresarial com as PPER voltadas à qualificação profissional. Os participantes levantaram como políticas com as quais mantêm 
mais contato: os cursos profissionalizantes oferecidos no SOS; os cursos técnicos oferecidos nos colégios, como de logística, de línguas, técnico-administrativo, técnico em farmácia ou atendimento, técnico em contabilidade, saúde bucal, eletromecânico etc.; os diversos cursos de qualificação oferecidos pela prefeitura; SENAC, SEST SENAT (com cursos de transporte), SENAI e SEBRAE; serviços da agência do trabalhador; os cursos ofertados na Universidade Estadual de Ponta Grossa (curso de inglês); o programa Jovem Aprendiz, que é proporcionado pela prefeitura por meio da Fundação de Assistência Social de Ponta Grossa (FASPG). Em se tratando de PPER, as empresas utilizam a intermediação de mão de obra oferecida pelo SINE.

Os entrevistados ressaltaram a importância das políticas públicas de emprego voltadas à qualificação profissional, afirmando que elas são benéficas tanto para a empresa como para os próprios trabalhadores. Na visão dos entrevistados das empresas, a qualificação torna o trabalhador mais preparado profissionalmente para o mercado de trabalho, favorecendo seu desenvolvimento na empresa e, consequentemente, promovendo a melhoria na produtividade das pessoas, na organização em que estão inseridas.

[...] o candidato que se apresenta já com uma formação é visto de forma diferenciada no mercado de trabalho, coloca-se como melhor preparado para enfrentar os desafios do dia a dia profissional. E para alguns casos, como motoristas e mecânicos, é pré-requisito que ele possua a qualificação requerida para o cargo, evidenciada através de certificação. (Entrevistada T).

Sobre empresas com parcerias com órgãos públicos que oferecem os cursos, foi possível concluir que apenas uma delas tinha parceria com a prefeitura na contratação de jovens aprendizes. Outras parcerias citadas foram com as instituições do Sistema S.

A respeito da dificuldade de encontrar mão de obra qualificada, alguns entrevistados citaram algumas funções específicas, como farmacêutico, classificador de grãos, operador de secador e operador de pá carregadeira, que ainda não são atendidas pelas políticas de qualificação profissional, e sugeriram que estas iniciativas fossem implantadas nessas áreas.

Neste sentido, poderiam ser incluídos outros cursos na qualificação profissional voltados para agroindústria; é notório que algumas áreas da economia têm uma necessidade crescente de trabalhadores qualificados em funções específicas que não estão sendo atendidas (Entrevistado M).

Todos os participantes sugeriram melhorias para as políticas voltadas à qualificação, para melhor atender a população e também as empresas, entre elas: 1) inserção de mais cursos durante a formação do ensino médio; 2) implantação de uma política voltada para área psicológica do trabalhador; 3) maior divulgação dos cursos e incentivo por parte dos órgãos públicos; 4) inclusão de cursos de qualificação profissional voltados para agroindústria; 5) promoção de atividades práticas nas empresas, permitindo maior aproximação entre a formação e a realidade; 6) maior aproximação dos órgãos para com as empresas no sentindo de promover parcerias.

Apesar de considerar que a política é benéfica, o entrevistado I sugere que os cursos oferecidos deveriam promover aos alunos trabalhadores mais vivências práticas da atividade dentro das empresas, para que assim o participante tenha uma maior aproximação entre a técnica e a realidade. Outro ponto que pode ser ajustado é a falta de comunicação dos órgãos que oferecem a política com as indústrias da região, no sentido de promover uma parceria, como estágios obrigatórios, por exemplo, a fim de oferecer aos alunos dos cursos experiência prática.

Neste ponto, com base nas orientações pautadas por Alves e Vieira (1995), para alcançar eficácia no equacionamento e solução dos problemas de qualificação, o governo, além de 
coordenar as suas intervenções na área de educação e de formação profissional, deve criar condições para a efetiva participação dos atores envolvidos na formulação das ações.

De modo particular, as empresas participantes da pesquisa prezam pela qualificação dos seus colaboradores, oferecendo constantemente cursos de atualização e aperfeiçoamento. Elas entendem que o que faz um funcionário qualificado permanecer em uma organização é a identificação com o ramo de negócios, bom clima organizacional, oportunidade de crescimento na empresa, com políticas de cargos e salários, plano de benefícios e, também, de ganho de conhecimento. Dessa forma, a valorização dos seus profissionais ocorre por meio de oportunidades de vagas internas, de crescimento no cargo, remuneração, na oferta de treinamento, premiações etc.

Acredito que a questão da remuneração é sim muito importante para a pessoa, até por que vivemos em um mundo capitalista, precisamos disso. Mas a satisfação ao conhecimento, acredito que é um grande diferencial nas empresas que querem manter seus colaboradores e seus funcionários que querem fazer um plano de carreira. Se você investir naquele funcionário, ele vai se sentir diferenciado, ele vai querer continuar na empresa sim. (Entrevistada F).

Nesta linha de percepção, Malschitzky (2002, p. 33) afirma que "[...] quanto maior a intensidade com que as pessoas e as organizações aprendem, mais condições existem para a criação de vantagens competitivas". Ou seja, a qualificação profissional pode resultar em uma vantagem competitiva para as organizações, podendo promover seu crescimento e, por conseguinte, o aumento de postos de trabalho, contribuindo para a geração de emprego e renda.

Em relação às estratégias empresariais para manter um profissional qualificado na organização, é importante destacar que a literatura traz como elementos que podem ajudar na retenção a remuneração fixa, remuneração variável, desenvolvimento de carreira, incentivo à capacitação e aprendizagem, qualidade de vida no trabalho, imagem da empresa, flexibilidade de horários, liberdade de criação, participação ativa em decisões (CHOWDHURY, 2003; ROBBINS, 2011).

Tratando-se da relação de escolaridade e qualificação com a produtividade, a TCH defende de forma clara que quanto maior for a escolaridade do trabalhador, mais habilidoso e, consequentemente, mais produtivo ele será. O propósito principal dessa teoria é mostrar que quanto mais escolaridade e qualificação tem um trabalhador, maior será a possibilidade de ter uma melhor remuneração (JACINTO, 2015). A seguir, apresentam-se as considerações finais do estudo.

\section{CONSIDERAÇÕES FINAIS}

As PPER praticadas atualmente funcionam como uma ponte entre trabalhadores e empresas, auxiliando na intermediação de mão de obra e na qualificação profissional gratuita. A aposta do governo federal na qualificação com o plano nacional de qualificação tem como objetivo não somente melhorar os índices de emprego formal, mas também gerar renda para a população, inserindo-a no "mundo do trabalho".

Este estudo identificou que as PPER são necessárias para auxiliar no equilíbrio do mercado de trabalho, principalmente nas questões do desemprego e da geração de renda. Por meio das entrevistas, verificou-se que quatro órgãos são os principais responsáveis por essas políticas na cidade de Ponta Grossa, PR. A Agência SINE é a que possui maior número de políticas voltadas para o fomento de empregos. Os dois órgãos ligados à prefeitura, SQ e SOS, têm como foco a 
qualificação profissional e a inserção de jovens e pessoas em situação de vulnerabilidade no "mundo do trabalho". Por fim, o CMT-PG é uma política especial criada para fiscalizar as políticas, expor novas necessidades e cobrar o Legislativo por novas leis que beneficiem o mercado de trabalho como um todo.

Durante as entrevistas, tanto com os órgãos quanto com as empresas, foi possível diagnosticar algumas necessidades que ainda precisam ser atendidas pelas políticas. Neste sentido, as propostas seriam: a) aumentar o investimento público nos cursos de qualificação profissional gratuitos que atendam às necessidades de todos os tipos de organizações empresariais, comércio, indústria e prestadores de serviços, para que assim as vagas de emprego ofertadas sejam preenchidas com mais facilidade pela agência; b) aumentar o número de cursos durante a formação do ensino médio, dando mais oportunidades para os jovens ingressarem no mercado de trabalho como profissionais qualificados; c) maior divulgação dos cursos gratuitos oferecidos e maior incentivo por parte das instituições públicas na participação da população; d) maior aproximação dos órgãos públicos com as empresas, para parcerias, no sentido de entender as necessidades das empresas e para, em conjunto, promoverem mais atividades práticas para as pessoas em formação nos cursos; e) oferecer aos trabalhadores que estão em busca de recolocação no mercado de trabalho uma política voltada para a área da saúde psicológica do trabalhador. Entende-se que as pessoas desempregadas, quando não amparadas de alguma forma, acabam com a saúde psicológica afetada.

Finalmente, conclui-se que as PPER da cidade de Ponta Grossa conseguem atender às demandas a que se propõem. No entanto precisam ser continuamente aperfeiçoadas, com direcionamentos mais específicos, incluindo políticas especialmente para as minorias. Além disso, o envolvimento de toda a comunidade - organizações empresariais, trabalhadores e instituições públicas - é essencial para alcançar os resultados planejados.

Esta pesquisa contribui para o meio acadêmico, na medida em que mostra a realidade das PPER em três visões diferentes: dos próprios órgãos que fazem as políticas acontecer; dos trabalhadores; e das empresas. Além de trazer a realidade para a academia, ela contribui também para o acervo de pesquisas com o mesmo tema, principalmente na área de administração, já que, como esclarecido anteriormente, ainda são incipientes as pesquisas com esse tema.

Como oportunidade de estudos futuros, sugere-se a realização de estudos semelhantes em outras cidades e estados, para que as realidades sejam comparadas e as ações de cada um sejam compartilhadas. Assim, as PPER poderiam ser aperfeiçoadas e renovadas para melhor atender a sociedade. Entende-se que as políticas públicas são a chave para auxiliar na criação de vagas formais de emprego, contribuindo com o desenvolvimento regional.

\section{REFERÊNCIAS}

ALMEIDA, E. P.; PEREIRA, R. S. Críticas à teoria do capital humano: uma contribuição à análise de políticas públicas em educação. Revista de Educação Pública, Cuiabá, v. 9, n. 15, p. 121-39, 2000.

ALVES, E. L. G.; VIEIRA, C. A. Qualificação profissional: uma proposta de política pública. Revista Planejamento e Políticas Públicas, Brasília, v. 1, n. 12, p. 117-44, 1995.

AMADEO, E. J.; ASSUNÇÃO, J. J.; FIRPO, S. P.; GONZAGA, G.; REIS, M. C.; ULYSSEA, G.; PESSOA, S. A. Instituições trabalhistas e desempenho do mercado de trabalho no Brasil. In: INSTITUTO DE PESQUISA ECONÔMICA APLICADA [IPEA]. Brasil: o estado de uma nação. Brasília: IPEA, 2006. p. 230-303.

INTERAÇÕES, Campo Grande, MS, v. 22, n. 2, p. 369-386, abr./jun. 2021 
BECKER, G. S. Human capital: a theoretical and empirical analysis, with special reference to education. 3. ed. New York: The University of Chicago, 1993. Disponível em: http://www.nber.org/books/beck94-1. Acesso em: 23 mar. 2018.

BETCHERMAN, G. Labor market regulations: what do we know about their impacts in developing countries? The World Bank Research Observer, Washington, v. 30, n. 1, p. 124-53, 2014.

BRASIL. Ministério do trabalho. Rede de atendimento. Brasília-DF, 2017. Disponível em: http://trabalho. gov.br/rede-de-atendimento. Acesso em: 15 fev. 2018.

BRASIL. Ministério do trabalho e emprego. Manual da aprendizagem: o que é preciso saber para contratar o jovem aprendiz. Brasília-DF: MTE/SIT/SPPE, 2014.

CASTRO, C. M. Educação no Brasil: atrasos, conquistas e desafios. In: INSTITUTO DE PESQUISA ECONÔMICA APLICADA [IPEA]. Brasil: o Estado de uma nação. Brasília: IPEA, 2006.

CHOWDHURY, S. A era do talento: obtendo alto retorno sobre o talento. Tradução de Sônia Midori. São Paulo: Pearson Education do Brasil, 2003.

COLBARI, A. L.; RAINHA, J. C. Arranjos institucionais "virtuosos" na dinâmica das políticas públicas de trabalho e renda. Revista de Pesquisa em Políticas Públicas, Brasília, v. 1, n. 3, 2014.

COUTINHO, A. R. Trabalho e qualificação profissional no trânsito das políticas. In: SILVA, L. A. M.; MADALOZZO, S.; MENDES, J. M. R. (Org.). Trabalho e proteção social. Ponta Grossa: Estúdio Texto, 2014.

CRESWELL, J. W. W. Projeto de pesquisa: métodos qualitativo, quantitativo e misto. 2. ed. Porto Alegre: Bookman, 2010.

FIGUEIREDO, M.; FIGUEIREDO, A. C. Avaliação política e avaliação de políticas: um quadro de referência teórica. Revista Fundação João Pinheiro, Belo Horizonte, v. 1, n. 3, p. 108-29, 1986.

FIELD, A. Descobrindo a estatística usando o SPSS. 2. ed. Porto Alegre: Artmed. 2011.

FLICK, U. Desenho da pesquisa qualitativa. Porto Alegre: Artmed, 2009.

FRIGOTTO, G. A produtividade da escola improdutiva. Um (re)exame das relações entre educação e estrutura econômico-social capitalista. 4. ed. São Paulo: Cortez, 1993.

GONÇALVES, C. A.; TEIXEIRA, K. M. D. Gênero e distribuição de renda: um estudo sobre o estado de São Paulo. Revista Gênero, Niterói, v. 18, n. 1, p. 56-74, 2017.

HERSEN, A. Decomposição dos diferenciais de rendimento do trabalho das regiões metropolitanas e não metropolitanas brasileiras. 2009. Dissertação (Mestrado em Desenvolvimento Regional e Agronegócio) - Universidade Estadual do Oeste do Paraná, Toledo, PR, 2009.

JACINTO, P. A. Produtividade nas empresas: uma análise a partir da escolaridade e da dispersão da produtividade. In: NEGRI, F.; CAVALCANTE, L. R. (Org.). Produtividade no Brasil: desempenho e determinantes. Brasília: ABDI/IPEA, 2015. v. 2.

KLOSOWSKI, L. A.; FERREIRA, M. S.; HERSEN, A.; TEIXEIRA, J. E. A dinâmica e o novo perfil do mercado de trabalho formal paranaense. Revista da RET, Rio de Janeiro, ano 6, n. 12, p. 81-98, 2013.

LUCAS JR., R. E. On the mecanics of economic development. Journal of Monetary Economics, Amsterdam, v. 22, n. 1, p. 3-42, 1988. 
MALHOTRA, N. Pesquisa de marketing: uma orientação aplicada. 4. ed. Porto Alegre: Bookman, 2006.

MALSCHITZKY, N. Empregabilidade $x$ empresabilidade: o ambiente empresarial deve estimular o desenvolvimento profissional. Revista FAE Business, Curitiba, v. 3, n. 2, p. 41-59, jun. 2002.

MARINHO, D.; BALESTRO, M.; WALTER, M. I. (Org.). Políticas públicas de emprego no Brasil: avaliação externa do Programa de Seguro Desemprego. Brasília: Verbis, 2010.

MARRAS, J. P. Administração de recursos humanos: do operacional ao estratégico. 14. ed. São Paulo: Saraiva, 2011.

MARTIN, J. P. Activation and active labour market policies in OECD countries: stylised facts and evidence on their effectiveness. IZA Journal of Labor Policy, Bonn, v. 4, n. 4, p. 1-29, 2015. https://doi.org/10.1186/ s40173-015-0032-y

MINARELLI, J. A. Empregabilidade: o caminho das pedras. 17. ed. São Paulo: Gente, 1995.

MINCER, J. Investment in human capital and personal income distribution. Journal of Political Economy, Chicago, v. 66, n. 4, p. 281-302, 1958.

PERET, E. Desocupação cai para 12,3\% no ano com recorde de pessoas na informalidade. IBGE Agência de notícias, [s.l.], 2018. Disponível em: https://agenciadenoticias.ibge.gov.br/agencia-noticias/2012agencia-de-noticias/noticias/23652-desocupacao-cai-para-12-3-no-ano-com-recorde-de-pessoas-nainformalidade. Acesso em: 14 abr. 2019.

POCHMANN, M. Ajuste econômico e desemprego recente no Brasil metropolitano. Estudos Avançados, São Paulo, v. 29, n. 85, p. 7-19, 2015.

PONTA GROSSA (Município). Lei n. 5400/96, de 14 de março de 1996. Institui o conselho municipal de emprego e relações do trabalho. Ponta Grossa, 1996.

REIS, M. C; RAMOS L. Escolaridade dos pais, desempenho no mercado de trabalho e desigualdade de rendimentos. Revista Brasileira Economia, Rio de Janeiro, v. 65, n. 2, p. 177-205, 2011.

ROBBINS, S. P. Comportamento organizacional. São Paulo: Prentice Hall, 2011.

ROSA, F. A. S.; ZAMPIER, M. P.; STEFANO, S. R. Tipos de carreira: análise da produção científica. Revista RECAPE, São Paulo, v. 7, n. 1, p. 358-73, 2017. https://doi.org/10.20503/recape.v7i1.32650

SCHULTZ, T. W. O valor econômico da educação. Rio de Janeiro: Zahar Editores, 1964.

SOUZA, C. Políticas públicas: conceitos, tipologias e subáreas. In: SOUZA, C. A função Administração Pública na Bahia. Salvador, EUFBA, 2002. p. 65-86.

VIANA, G.; LIMA, J. F. Capital humano e crescimento econômico. Interações, Campo Grande, v. 11, n. 2, p. 137-48, 2010.

\section{Sobre os autores:}

Fernanda Almeida da Silva Rosa: Mestra em Administração pela Universidade Estadual do Centro-Oeste (UNICENTRO). Bacharela em Administração pela Unicentro. E-mail: fer_almeida-silva@hotmail.com, Orcid: http://orcid.org/0000-0002-5601-3535 
Silvio Roberto Stefano: Pós-Doutor em Gestão pela Universidade do Porto. Professor associado do Programa de Pós-Graduação em Administração (PPGADM) e Multidisciplinar em Desenvolvimento Comunitário (PPGDC) da Universidade Estadual do Centro-Oeste (UNICENTRO). E-mail: professor-silvio@hotmail.com, Orcid: http://orcid.org/0000-0002-5871-8686

Luiz Fernando Lara: Doutor em Ciências Sociais pela Pontifícia Universidade Católica de São Paulo (PUC-SP). Professor adjunto do Departamento de Administração da Universidade Estadual de Ponta Grossa (UEPG), e do Programa de Pós-Graduação em Administração (PPGADM) da Universidade Estadual do Centro-Oeste (UNICENTRO). E-mail: Iflara2010@gmail.com, Orcid: http://orcid.org/0000-0002-1258-7019

Márcio Luiz Bernardim: Doutor em Educação pela Universidade Federal do Paraná (UFPR). Professor Adjunto do Departamento de Administração da Universidade Estadual do Centro-Oeste (UNICENTRO). E-mail: marcio.bernardim@gmail.com, Orcid: http://orcid.org/0000-0003-3639-7938 